\title{
Stability analysis of MSW slope layered by aging
}

\author{
Xinping Fan ${ }^{\text {i) }}$, Maosong Huang ${ }^{\text {ii) }}$, Yilin Liiii) and Haoran Wang ${ }^{\text {iv) }}$ \\ i) Ph.D. Student, Department of Geotechnical Engineering, Tongji University, Shanghai 200092, China. \\ ii) Professor, Department of Geotechnical Engineering, Tongji University, Shanghai 200092, China. \\ iii) Professorial Research Fellow, Research Institute of Highway Ministry of Transport, Beijing 100088, China. \\ iv) Engineer, Shanghai Urban Construction Design \& Research Institute, Shanghai 200125, China.
}

\begin{abstract}
As the age of waste changes, the strength of the waste varies during the service years of the landfill. On base of the upper bound limit analysis theorem, two mechanisms for stability analysis of landfills layered by aging are presented in this paper. The rotational-translational mechanism is generalized to analyze the multi-layer municipal solid waste (MSW) landfill slope. The other failure mechanism is comprised of irregular blocks undergoing translational movements. To examine the two mechanisms, the cases of a soil slope layered horizontally and a landfill slope layered by aging are taken into consideration in the case studies. In comparison with the results from the shear strength reduction finite element method (SSRFEM), it demonstrates that the validity of the two mechanisms in the stability analysis of landfill slope cases considering the aging of landfills. In addition, the stability of the Coll Cardús in Spain with complex layers by aging is analyzed, and the results are also compared with those from the SSRFEM.
\end{abstract}

Keywords: Landfill; age; stability; rotational-translational; multi-block; numerical simulation

\section{INTRODUCTION}

The difference between landfill slopes and other general soil slopes is the specific character of MSW. During the term use of landfill, the degree of degradation of waste is diverse because the time of waste buried is different. The shear strength has distinct differcence. Chen et al. (2009) obtained the relationship between waste compositions and age by the test analysis of the borehole samples from the Suzhou Qizishan Landfill. With the fill age, the strength of the waste changed, including that friction angle increasedand cohesion decreased. Machado et al. (2002) and Feng et al. (2007) gained the similar conclusions. Hence, it is necessary that landfill slopes are layered by aging when the stability is analyzed.

Recently severalscholars have analyzed the stability of the landfill slopes by the limit equilibrium method (LEM). Qian et al. (2003) and Qian \& Koerner (2004) used the limit equilibrium method to analyze the landfill slopes. In their studies, the sliding mass was splited into two wedges, the active wedge and the passive wedge. The equilibrium function was set up to obtainthe safety factor after analyzing the two wedges. Hossain et al. (2009) analyzed the stability of the MSW slope considering four different fill ages by the finit element method (FEM) and LEM.

In this paper, the landfill slope layered by aging is analyzed by two failure mechanismsbased on the limit analysis method. One is the rotational-translational mechanism; and the other is the multi-block
mechanism.At first, a typical soil slope layered horizontally is analyzed by the limit analysis method to demonstrate the valid of the two mechanisms in the stability analysis of the slope. Then the case of the landfill slope layered by aging is analyzed by the two mechanisms above. Their results are consistent with that from the shear strength reduction finite element method (SSRFEM). Finally, these two mechanisms are applied to calculate the stability of the Coll Cardús landfill in Spain with complex layers by aging. Again, good agreement with the SSRFEM can be found.

\section{UPPER BOUND LIMIT ANALYSIS}

\subsection{Upper bound theorem}

The limit analysis method in this paper is based on the upper bound theorem, which states that the rate of external work is less than or equal to the rate of internal plastic energy dissipation in any kinematically admissible velocity field (Michalowski, 1995). This can be expressed as

$$
\int_{S} T_{i} v_{i} d S+\int_{V} X_{i} v_{i} d V \leq \int_{V} \sigma_{i j} \dot{\varepsilon}_{i j} d V(i, j=1,2,3)
$$

\subsection{Rotational-translational mechanism}

Because of the liner systemin the landfill, the limit analysis is based on the rotational-translational mechanism rather than the conventional rotational failure mechanism for homogeneous slopes. As show in Fig. 1, the wedge $\mathrm{A}$ is the rotating block, and the wedge $\mathrm{B}$ is the translating block. It is assumed that the 


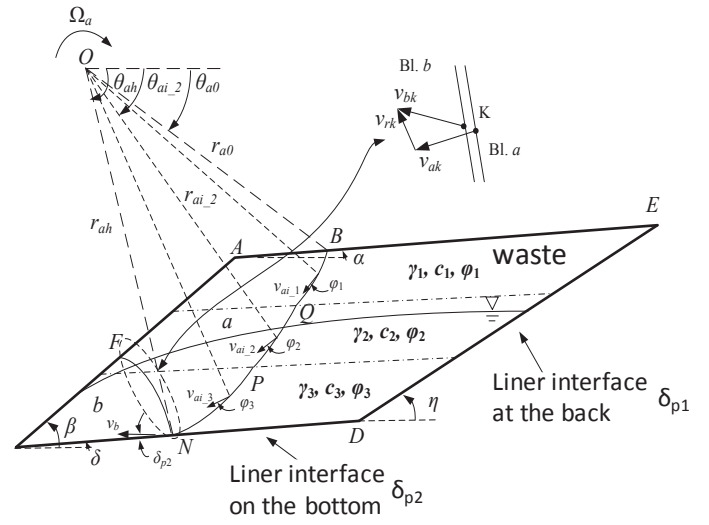

Fig.1 Rotational-translational mechanism of a landfill slope layered by ageing

failure surface (the $\mathrm{BN}$ part) is a logarithmic spiral rotating around the point $O$. The wedge B translates along the liner system. The velocity of the wedge B is $v_{b}$, of which direction is tilted $\delta_{p 2}$ relative to the liner interface on the bottom. The layers in the wedge A rotates with the same angular velocity. The three sections (NP, PQ and QB) are tilted respectively $\varphi_{1}$ 、 $\varphi_{2} 、 \varphi_{3}$. The velocity of the gap FN between the wedge $\mathrm{A}$ and $\mathrm{B}$ is $v_{\mathrm{raK}}$

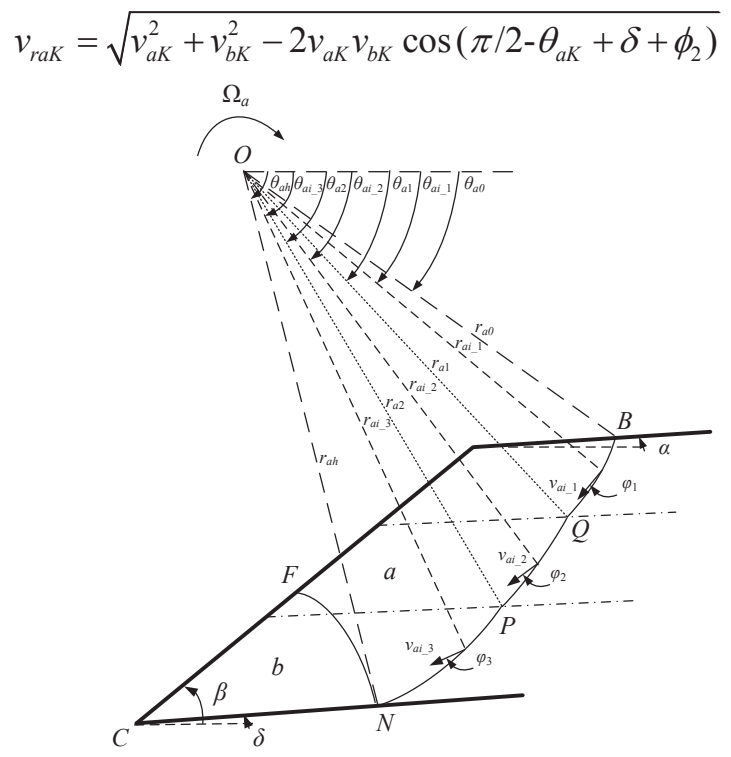

Fig.2 Velocity fieldsof the rotational-translational mechanism

In the calculative process, it is worth nothing that the frictional angle should be consistent with the corresponding layer that the gap contains. After constructing the kinematically admissible velocity field (Fig.2), the safety factor can be obtained by Eq. (1).

\subsection{Multi-block mechanism}

Similar to the rotational-translational mechanism, the upper bound limit analysis can be performed with the multi-block mechanism. In the analysis of the slope stability, the rotational-translational mechanism is a simplified model, of which the wedge number is not large.And the sliding surface should not be complicated. However, the multi-block mechanism is a global searching model. The number of blocks in the multi-block mechanism is large, so the failure surface can be any shape.

The sliding mass is divided into $n$ blocks to build the velocity field (Fig. 3). The velocity of the block $i$ is $v_{i}$. When the block $i$ is translating along the liner system, the direction of $v_{i}$ is tilted $\delta_{p 2}$ relative to the liner interface on the bottom. When the failure surface is through the sliding mass, the direction of $v_{i}$ is tilted $\delta_{i}$ (the frictional angle of the corresponding soil layer) relative to the failure surface. The velocity of the block $i-1$ is $v_{i-1}$, and the relative velocity of the block $i$ and $i$ 1 is $[v]_{i}$. On the assumping that the velocity of the block 1 is $v_{1}$, the kinematically admissible velocity field is constructed. And the safety factor can be obtained by Eq.(1).

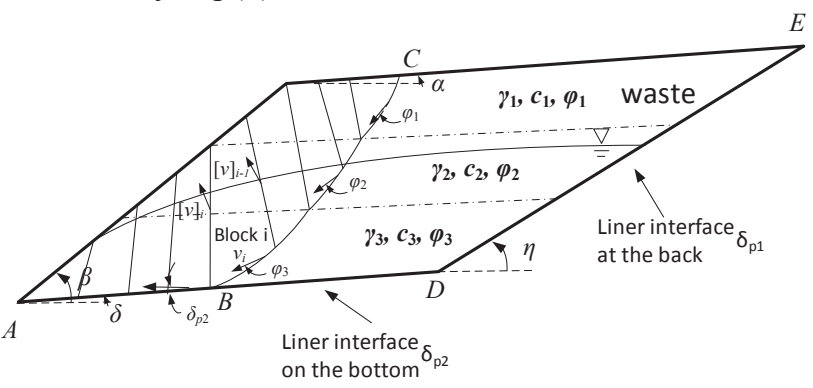

Fig. 3 Multi-block mechanism of a landfill slope layered by ageing

\section{CASE STUDIES}

\subsection{Case 1: a layered soil slope}

Case 1 (Fig. 4) is a layered soil slope which was previously studied by Bui et al. (2011) with the elastoplastic smoothed particle hydrodynamics ( $\mathrm{SPH})$. This case is studied again to verify the suitability of the two mechanisms for the limit analysis. Table 1 shows the parameters of soils used in the analysis. The case is also analyzed by the SSRFEM as well as the LEM. Comparisons with the SSRFEM, SPH and LEM are summarized in Table 2.

As shown in the table, the safety factors obtained from variousmethods are similar. The critical failure modes of the slope (Fig. 5) are almost the same. The result of the rotational mechanism is slightly better than that of the multi-block mechanism, since the failure surface of this slope is close to a circlar arc other than the multi-polyline found in the multi-block mechanism. It can be conclued that even if the number of blocks in the multi-block mechanism is very large, the critical failure mode is different from the theoretical mode. 


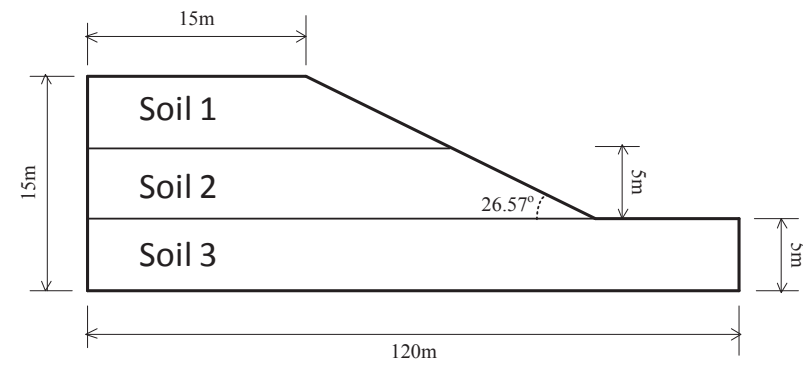

Fig.4Geometry of the soil slope

Table 1 Parameters of the soils (Case 1)

\begin{tabular}{cccc}
\hline & Soil 1 & Soil 2 & Soil 3 \\
\hline Unit weight & $18 \mathrm{kN} \cdot \mathrm{m}^{-3}$ & $19.5 \mathrm{kN} \cdot \mathrm{m}^{-3}$ & $21 \mathrm{kN} \cdot \mathrm{m}^{-3}$ \\
Cohesion & $14 \mathrm{kPa}$ & $16.8 \mathrm{kPa}$ & $19 \mathrm{kPa}$ \\
Frictional angle & $18^{\circ}$ & $20^{\circ}$ & $23^{\circ}$ \\
Elastic modulus & $60 \mathrm{MPa}$ & $80 \mathrm{MPa}$ & $100 \mathrm{MPa}$ \\
Poisson's ratio & 0.3 & 0.3 & 0.3 \\
\hline
\end{tabular}

Table 2 Factors of safety (Case 1)

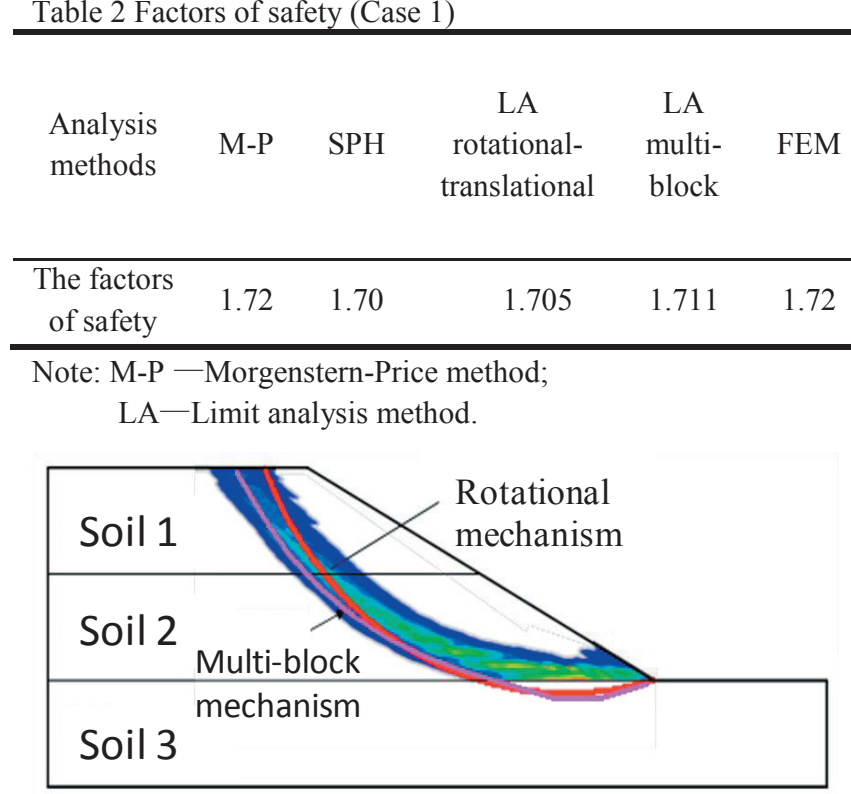

Fig. 5 Critical failure modes of the soil slope

\subsection{Case 2: a landfill slope layered by aging}

A case of the landfill slope is analyzed by considering the fill age here. The geometry of the landfill slope is showed in Fig. 6 with $\mathrm{L} / \mathrm{H}=4.5$. The fill age of the waste is divide to low, middle and high levels. Parameters of the waste aregiven in Table 3.

At first, the homogeneous landfill slopes whose fill ages are in the low, middle and high levels respectively are analyzed by the limit analysis method and SSRFEM. The results are listedin Table 4. Then the landfill slope layered by aging are studied. The failure surfaces obtained by the two mechanisms and the plastic strain contourare shown in Fig.7. The plastic strain contour shows that the failure surface moves along the liner syestem on the bottom and goes through the waste mass. And the safety factor obtained by the limit analysis method is close to that by FEM.The safety factor by the multi-block mechanism is smaller than that by the rotational-translational mechanism, which is mainly because the largernumber of wedges in the multi-block mechanism can obtain the more reasonable failure surface.

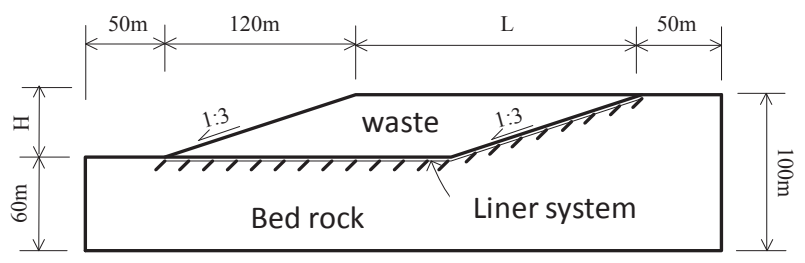

(a)

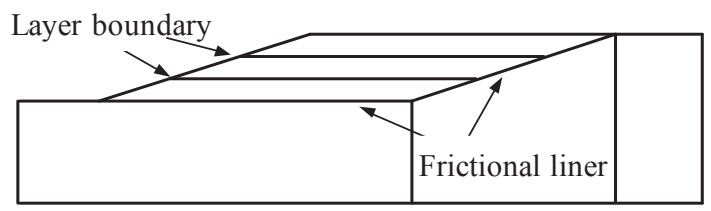

(b)

Fig.6Geometry of the landfill slope

Table 3 Parameters of the waste (Case 2)

\begin{tabular}{cccc}
\hline & low & middle & high \\
\hline Unit weight $\left(\mathrm{kN} / \mathrm{m}^{3}\right)$ & 13 & 13 & 13 \\
Cohesion & $30 \mathrm{kPa}$ & $25 \mathrm{kPa}$ & $20 \mathrm{kPa}$ \\
Friction angle & $15^{\circ}$ & $20^{\circ}$ & $25^{\circ}$ \\
Elastic modulus & $5 \mathrm{MPa}$ & $5 \mathrm{MPa}$ & $5 \mathrm{MPa}$ \\
Poisson's ratio & 0.3 & 0.3 & 0.3 \\
\hline
\end{tabular}

Table 4 Factors of safety (Case 2)

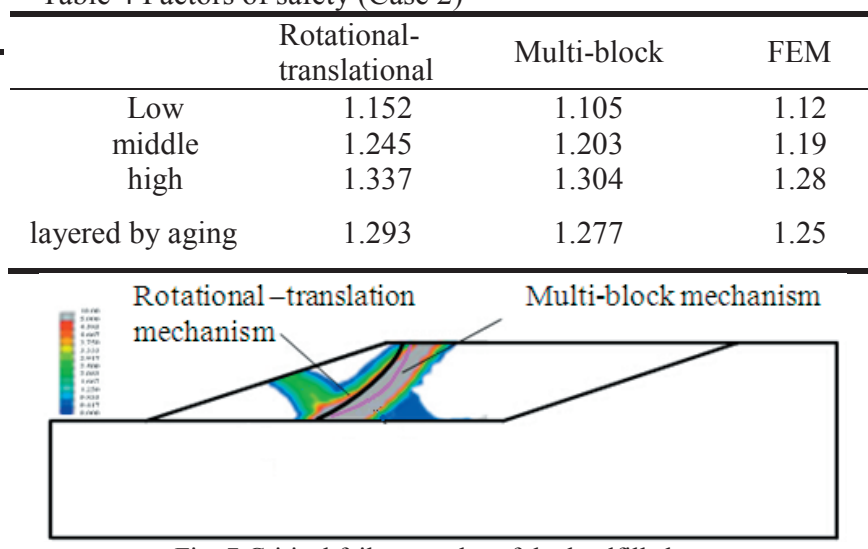

Fig. 7 Critical failure modes of the landfill slope

As shown in Table4, the larger safety factor can be obtained when the waste has the larger fill age. So the landfill slope becomes stable with the fill age increasing in the absent of pore pressures. And the safety factor of the landfill slope layerd by aging (multi-block mechanism for example, 1.277) is between that of the homogeneous slope with the middle (1.203) and high (1.304) fill age level.

\subsection{Case 3: the Coll Cardús landfill in Spain}

The the CollCardús landfill is located at the northeast of Spain, and it has worked from 1980s. The waste was directly dumped in a natural valley. The height of the waste mass was around $150 \mathrm{~m}$ as shown in Fig. 8 (Yu and Batlle, 2011). In the 2D analysis of its stability, the A-A section is selected which has the most risk. Fig. 9 shows the calculation mode. And the parameters of the waste are in the Table 5 . 


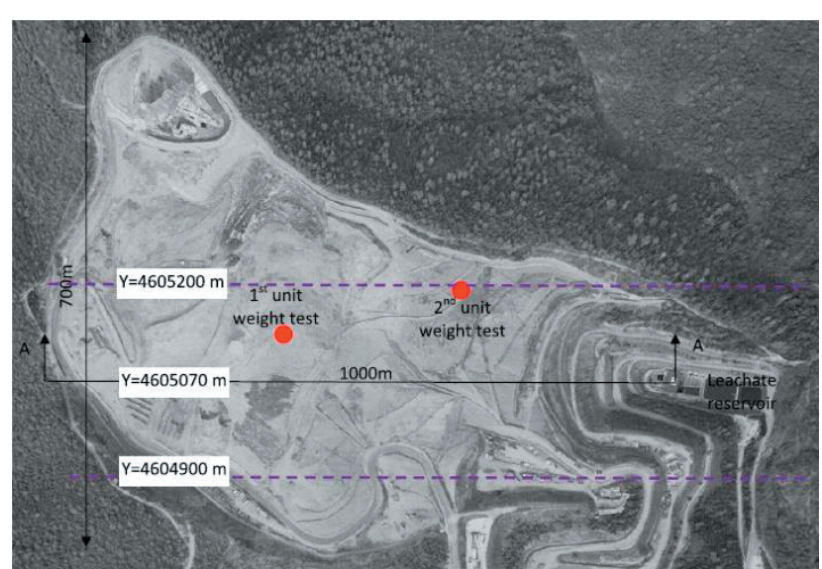

Fig. 8 Aerial view of the Coll Cardús landfill (Yu and Battle, 2011)

The safety factor obtained by the multi-block mechanism is smaller than that by the rotationaltranslational mechanism (Table 6). This is mainly owing to that the global search is used in the multiblock mechanism, while the local search is used in the rotational-translational mechanism. The factors of safety obtained by the two mechanisms are close to that by the SSRFEM, and the critical failure modes are also simlar (as shown in Fig.10).

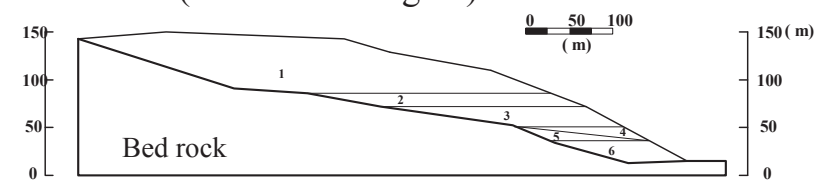

Fig. 9 Analyzed cross-section of the Coll Cardús landfill

Table 5 Parameters of the waste (the Coll Cardús landfill)

\begin{tabular}{crrrrrr}
\hline Fill age $($ years $)$ & 5 & 8 & 10 & 12 & 17 & 22 \\
\hline $\begin{array}{l}\text { Unit weight } \\
\left(\mathrm{kN} \cdot \mathrm{m}^{-3}\right) \\
\text { Cohesion } \\
(\mathrm{kPa})\end{array}$ & 18.5 & 18.5 & 18.5 & 18.5 & 18.5 & 18.5 \\
$\begin{array}{c}\text { Friction angle } \\
\left({ }^{\circ}\right)\end{array}$ & 15 & 19 & 23 & 27 & 31 & 35 \\
$\begin{array}{c}\text { Elastic modulus } \\
(\mathrm{MPa})\end{array}$ & 7 & 7 & 7 & 7 & 7 & 7 \\
\hline
\end{tabular}

Table 6 Factors of safety (the Coll Cardús landfill)

\begin{tabular}{cccc}
\hline $\begin{array}{c}\text { Analysis } \\
\text { method }\end{array}$ & $\begin{array}{c}\text { Rotational- } \\
\text { Translational }\end{array}$ & $\begin{array}{c}\text { Multi- } \\
\text { block }\end{array}$ & SSRFEM \\
\hline $\begin{array}{l}\text { Safety } \\
\text { factors }\end{array}$ & 1.268 & 1.232 & 1.24 \\
\hline
\end{tabular}

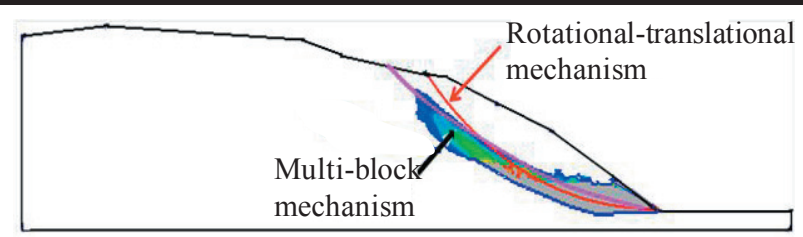

Fig.10 Critical failure modes of the Coll Cardús landfill slope

\section{CONCLUSIONS}

In this paper, two failure mechanisms have been proposed for the upper bound limit analysis method to analyze the stability of the landfill slopes layered by aging. The layered soil slope, the landfill slope layered by aging and the Coll Cardús landfill in Spain have been analyzed by the above-mentioned method. The studies indicate:

(1) In comparison with the results of finite element methods, it demonstrates that the validity of the two mechanisms in the stability analysis of landfill slopes considering the aging of landfills.

(2) The more reasonable result of the analysis by the rotational-translational mechanism can be obtained when the failure surface is close to a circular arc. For the case of the landfill slope layered by aging, which failure surface is irregular under the complicated condition, analyses with the multi-block mechanism will lead to more reasonable results.

(3) As the fill age increases, the landfill slope becomes stable in the absent of pore pressures. The fill age is divided into low, middle and high levels. The safety factor of the landfill slope layered by aging is between those of the homogeneous slopes with the middle and high fill age levels.

\section{ACKNOWLEDGEMENTS}

This work was financially supported by the National Basic Research Program of China (973 Program, Grant No.2012CB719803). This support is gratefully acknowledged.

\section{REFERENCES}

1) Chen, Y-M., Lin, W-A., Zhan, L-T. (2009): A study on the relationship between the shear strength of municipal solid waste and the fill age. China Civil Engineering Journal, 3, 111-117.

2) Machado, S. L.,Carvalho, M. F., Vilar, O. M. (2002): Constitutive model for municipal solid waste. Journal of Geotechnical and Geoenvironmental Engineering, 128(11), 940-951.

3) Feng, S-J., Chen, Y-M., Gao, G-Y. (2007): Analysis on translational failure of landfill along the underlying liner system. Chinese Journal of Geotechnical Engineering, 29(1), 20-25.

4) Qian, X., Koerner, R.M., Gray, D.H.(2003): Translational failure analysis of landfills[J].Journal of Geotechnical and Geoenvironmental Engineering, ASCE, 129(6), 506-519.

5) Qian X., Koerner, R.M.(2004): Effect of apparent cohesion on translational failure analysis of landfills." Journal of Geotechnical and Geoenvironmental Engineering, ASCE, 130(1), 71-80.

6) Hossain M. S., Haque, M.A. (2009): Stability Analyses of Municipal Solid Waste Landfills with Decomposition. Geotechnical and Geological Engineering,27(6), 659-666.

7) Michalowski, R. L. (1995):Slope stability analysis: a kinematical approach. Geotechnique, 45(2), 283-293.

8) Bui. H. H., Fukagawa, R., Sako, K.(2011): Slope stability analysis and discontinuous slope failure simulation by elasto-plastic smoothed particle hydrodynamics (SPH). Geotechnique, 61(7), 565-574.

9) Yu, L., Batlle, F. (2011): A hybrid method for quasi-threedimensional slope stability analysis in a municipal solid waste landfill [J]. Waste Management, 31(12), 2484-2496. 